\title{
Green Event Management and Initiatives for Sustainable Business Growth
}

\author{
Nor Lela Ahmad, Wan Edura Wan Rashid, Norfadzilah Abd Razak, Ahmad Nizam Mohd. Yusof, and \\ Noor Syahieda Mat Shah
}

\begin{abstract}
Organizing events are highly resource intensive, and can have negative environmental consequences such as waste of water, energy and materials. Therefore, greening our event is critically important to ensure sustainability development in event management by making responsible decisions during planning, organization and implementation of an event. Thus, the objectives of this paper are; i). to define the characteristics of a green event, ii) to develop a plan to organize a sustainable event, iii) to explore some of the issues encompassing the management and staging of a green event and iv) to examine the importance of engaging a range of key stakeholders and considers various ways in which events are greening their operations. Next, the framework of this research focuses on the initiatives such as energy efficiency, waste minimization, water consumption and eco-procurement that will impact on awareness and sustainable development. The finding of this research will educate, motivate and create awareness to different classes, races and religions to come together as one and actually care for the environment during events. Practically, the finding of this study will also help to discover an extensive knowledge on event management with the key result area of application in sustainability and green technology initiatives.
\end{abstract}

Index Terms-Green event management, sustainability, planning, initiatives, business growth

\section{INTRODUCTION}

Globally, more and more events are hosted in an environmentally, socially and economically responsible way. Many international companies are making event greening a part of their tender process. Greening our event should reduce the negative environmental impact, but should also leave a positive and lasting legacy for the local community. Hosting an event requires great amounts of water, energy, and materials that result in waste and greenhouse gas emissions [1]. Many event organizers and venue managers would like to reduce their impacts on the environment but may not be sure how to start. It is crucial to involve all of the stakeholders that play a role in the planning or producing of the event. If there is no commitment from the leadership, efforts may be ineffective and unnoticed. If commitment from leadership is engaged, they need to communicate this fact with all other partners involved to make sure full cooperation from the whole organization [2]. The sooner an

Manuscript received June 20, 2013; revised August 26, 2013.

The authors are with Faculty of Business Management, Universiti Teknologi MARA, Malaysia (e-mail: norlela7676@gmail.com, wanedura@yahoo.com, anizammy@gmail.com and adeihays@yahoo.com). organization starts this process the better.

Planning ahead is the single most important element in achieving a successful event. It involves including sustainable development principles and practices in all levels of event organization, and aims to ensure that an event is hosted responsibly. It represents the total package of interventions at an event, and needs to be done in an integrated manner. Event greening should start at the inception of the project, and should involve all the key role players, such as clients, organizers, venues, sub-contractors and suppliers [3]. The event industry and its related sectors have weathered much of the criticism for making a large contribution to environmental pollution. With its exponential growth over the past decade or so, the event sector is drawing attention as an increasing contributor to this global problem. Currently, there is a paucity of academic literature which examines the relationship between events and the environment. Organizers of events are increasingly looking to highlight their green credentials [4]. This is occurring against the background of an increasingly sophisticated market that is suspicious of claims that cannot be substantiated.

The evident is that every event organization, irrespective of size, scale or scope, is intertwined with the natural flow of consumption and outcomes. It is the nature and volume of these inputs and outputs that is especially important [5]. In this study, environmental responsibility can be seen as a fundamental aspect of social responsibility, and a mechanism to longevity within a changing event environment. [6] exemplify this by clarifying environmental concerns within a sport event organization. It is in everyone's interest for all businesses, in every industry, to make environmental sustainability a management competency and an aspect of organizational excellence. By taking environmental responsibilities seriously, organizations in the sport event industry are uniquely positioned to communicate the value of environmental sustainability to large numbers of people. Fulfilling environmental responsibilities can help the firm gain a competitive edge and create greater value for its owners. Whenever, wherever we gather - whether it is for a reception, a festival, a meeting or a convention - we have opportunities to make a positive difference for the environment. Event planners are the central figures in any event, affecting the choices and experiences of a constellation of suppliers, facilities, caterers, sponsors and attendees [7]. Greening is about progress, not perfection. Sustainability does not happen with one event. Start now and every subsequent decision and action will present opportunities for continuous improvement. Similarly, 
sustainable event design will evolve with the times and event planners will learn from experience and each other.

Apparently, sustainable management is very important to the event industry. Throughout this theme issue practitioner, pioneers and academics have revealed a change in the way in which event managers need to respond to consumer demand; the way in which the industry responds to political pressure, legislation, the competitive environment and future glimpses into supply chain management and market trends. [8] and [9] corroborate each other's work and posit that events need to be cognizant of social impacts, an evaluation of these impacts and its impact upon the "triple-bottom line" model. Equally, it is the public sector's heightened awareness of these implications, as opposed to a singular economic perspective, that has given rise to such concerns within this industry. In agreement, [10] question the long-term viability of events and suggest that events have a low probability of reoccurrence if event-specific objectives are not related to social and environmental values of the local community. Literature proposes that events can differ in their impacts but potentially these impacts relate to dimensions of economic, tourism/commercial, bio-physical, socio-cultural, psychological, political, human and environmental concerns as indicated in [11] and [12]. Presently, the impact of events can be classed by pre- and post-event evaluation to evaluate potential risk/exposure - ecological, infrastructure, community and financial, enhanced prestige and catalyst for infrastructure development and the economic impact at region and national level, community attitudes, image/destination enhancement and potential future event/business opportunities [13].

Therefore, this research is designed to fulfill the following objectives:

- To define the characteristics of a green event,

- To develop a plan to organize a sustainable event,

- To explore some of the issues encompassing the management and staging of a green event,

- To examine the importance of engaging a range of key stakeholders and considers various ways in which events are greening their operations.

\section{LITERATURE REVIEW}

\section{A. Energy Efficiency}

Energy is a vital daily resource and one for which demand is growing rapidly. Considering that half of the global population now live in urban areas, that natural resources are dwindling, and that climate change is one of the main challenges facing us today, it is clearly time to change the way we use energy - and to reduce our impact on the environment [14]. Sustainable energy management is a far-reaching concept that covers all phases of the sector from fuels and their extraction, to energy generation and the systems' efficiencies, energy distribution, and energy consumption (in terms of amount and efficiency), and energy security implications etc.

When managing energy, it is necessary that consequences are considered beyond the local level. Global aspects must be taken into account, such as the environmental, economic and social results of fuel extraction and transportation from its source to its destination. Sustainable energy management should not be conducted as an isolated operation. Many other systems depend on and interact with the energy system. Energy management is one of the layers of community management as a whole, and hence the principles of sustainability should ideally be applied in a cross-sectoral, integrated approach, beyond strictly energy themes [15]. The challenge with energy management is that the amount of energy being consumed is usually not instantly apparent. Unlike waste, which provides a visual cue of its impact on the environment, energy is much harder to quantify and is often taken for granted and treated as an unavoidable cost [16].

\section{B. Waste Minimization}

The focusing question for a consideration of waste was, what is the real impact of different approaches to processing and waste and how does this put consumption into context? Initially, this can be viewed from four perspectives. First, in effect, waste is the disposal of something that has/had value. After all it was purchased. Disposal often has a cost, in that you may have to pay to have it removed and then pay tax on top of that [17]. An overall context has to be considered for waste. Waste is fundamentally bad in terms of damage to the environment but also erodes economic efficiency. If a caterer is wasting products that have been produced in a sustainable way then it is possible to actually negate the environmental benefit that has been accrued [18]. Re-cycling waste at an event makes sustainable sense but, perhaps, not if that waste creates further planet problems by being transported some way for the recycling process to happen, or, that cheap labour is required to separate the waste causing people issues. From this, the importance of individual responsibility at the consumer side and organizational responsibility at the supply side of an event can be seen to affect the overall sustainability of an event [14].

In terms of waste, measuring and reporting may be the key to working with such clients to reduce this aspect of the impact of their events. Statistics revealing the amount of waste diverted from landfill, and particularly those which demonstrate a cost saving for the client, can be a powerful means of addressing a client's concerns [11]. Being able to show a client how waste reduction techniques can work in practice can also help to alleviate any anxiety the client may have around the effectiveness or practicality of such changes. With these new waste regulations being brought in, there is an expectation that waste management will become more complex and thus charges will rise. The extent to which these cost increases are passed down the supply chain may have a significant impact on the attractiveness of waste reduction. If successful, these regulations should increase the amount of life-cycle planning and designing out of waste, and push waste minimisation up the agenda for clients.

\section{Water Consumption}

With only 0.007 per cent of the earth's water available for us to drink, water is fast becoming the next key issue in sustainability. The EU Framework Directive provides guidance to Member States on the protection of the integrity 
to their water supplies, including quality deterioration, pollution and release to water of hazardous substances. Providing jugs of tap water at an event has long been held as best practice, but that was more to do with the manufacture, disposal and transportation of the bottle, rather than concerns over global water supplies. Yet, the uptake of this simple technique has been slow, making it difficult to move beyond it and look for the next innovative approach.

\section{Eco-Procurement}

Green procurement would seem to be a fairly simple concept. It would involve developing supply chains that delivered goods (food), of a type and in a way, which minimized the impact onthe environment. Minimizing environmental impact would seem, at least initially, to be a reasonable working definition of "green" in this context [2]. A cap on oil consumption by 2025 will impose green procurement options [19]. This is already evident within "the green procurement code" London, and transparency of supply chain within the food sector, ethical supply chain standards, "fair-trade" and others. Moreover, [20] report, suggests threshold industry standard will drive life-cycle analysis reporting through the value chain and initiatives such as the Global Reporting Initiative and standards like PAS 2050 will be seen as entry-level management standards for many types of events. The Clinton Climate Initiative acknowledges the opportunity that the carbon economy can provide. It announced that the creation of skills, specific to carbon neutral technology, will encourage frameworks and models which should be adopted elsewhere and mould, influence and move sustainable practice to developing countries and markets [21].

\section{E. Communication}

Communications involve more than legitimacy alone because they also feature an instrumental dimension that deserves further exploration. [8] found the novelty in sustainability communications does not lie in companies' recent commitment to social responsibility but in the fact that they have started to publish objectives and approaches that were once implicit. Citizen companies and responsible managers have been around for a while but the publication of formalized commitments has become compulsory in corporate institutional communications.

\section{F. Awareness}

Creating a green culture often involves reinforcing behavior that people already want to adopt, but there is still a need for the appropriate tools and training in order to change. Businesses that cultivate a green culture today are often immediately noticeable to outside visitors as unique, and at other times the differences in a green culture are imperceptibly small. For the former, an environmentally sound culture is often part of the core business strategy to encourage "green" considerations in every decision that is made [22]. A green strategy should generally lead to cost effective transformation initiatives that meet or exceed regulatory requirements. Still, understanding benefits that are typically qualitative is critical to understanding the total green value proposition.
Green value propositions will include benefits to the company environment (buildings and facilities), benefits to the community, and improvements to the global environment [23]. [15] indicates that for a business to operate towards sustainability, it should start "with the belief that we are part of a larger system - a business ecology - and extends the willingness to examine the larger socio economic system and how we impact it at the individual, community, and organizational levels, and eventually at the planetary level." This provides the necessity to incorporate the systems approach which can help in the identification and solution of environmental problems through a holistic vision towards sustainability [8].

\section{G. Sustainable Development}

Sustainable development involves considering environmental, economic, and social objectives when developing and implementing public policies and programs. It also involves considering the needs of the present as well as the needs of future generations. Integrated decision making and a long-term approach to planning are defining characteristics of sustainable development and represent the key management challenges as concluded by [24] and [25].

\section{CONCEPTUAL FRAMEWORK}

In order to conduct this study, green event management is served as independent variable or input which comprises four major constructs: energy efficiency, waste minimization, water consumption and eco-procurement. On the other hand, awareness and sustainable development are labeled as the dependant variable. The past literature has proven the emergence of communication in mediating the link between green event management and the level of awareness that will contribute towards sustainable development. Thus in this framework, communication is included as a mediator between independent variable and dependent variable. Therefore, this study proposes the following framework that is illustrated in Fig. 1.

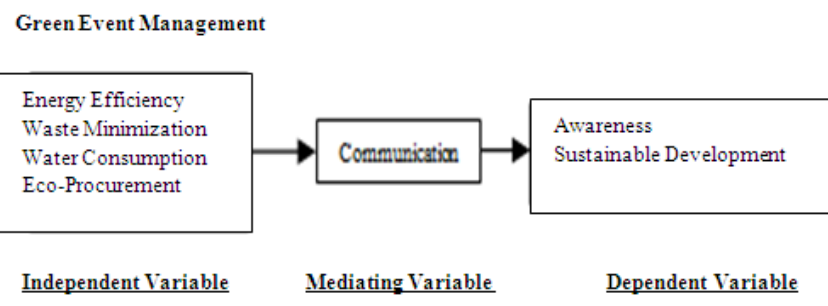

Fig. 1. Proposed conceptual framework.

\section{CONCLUSION}

The findings of this study will not only advance the body of knowledge within this academic field, but will also help relevant parties to develop better event management practices to improve business services that will contribute towards society transformation and increase the quality of life. Organizations should take the initiatives to encourage sustainable management in all aspects of their operation. We are mainly focusing on the area of event management. The researchers would propose the following recommendations: 


\section{A. Energy Efficiency}

The research would recommend utilizing natural light and ventilation to reduce energy consumption. When lights need to be used ensure that they are energy efficient. Event organizers must ensure that they request energy efficient or energy star rated products such as computers or printers for their event. They should also request for the electricity meter readings before, during and after the event for monitoring electricity usage to reduce consumption for future events. The organizers must endeavor to switch off all lights and air-conditioners when leaving the room/venue.

\section{B. Waste Minimization}

Event organizers should try to avoid printed handouts and if it is essential, then use recycled or eco-friendly paper. The person in charge should save important documents to a USB flash drive to reduce paper use and encourage reuse instead of disposal. The research also recommends requesting recycle bins from the venue to encourage waste separation at source and reduce waste to landfill.

\section{Water Consumption}

The authors would also like to recommend that event organizers select venues that implement water conservation practices through policies and action as well as making delegates aware of these. Logistic options should select accommodation establishments that promote water conservation policies such as towel/linen laundry policies where delegates can choose to replace or reuse the towels or linen in their rooms.

\section{Eco-Procurement}

Event organizers should make sure their purchasing power is fully exercised when choosing venues that implement environmental practices such as energy efficiency and waste reduction. In issuing and Purchase Order, they should request products that are eco-friendly and locally manufactured. The event organizers should request food that is local, seasonal and organic whenever possible. Ensure that products are sustainably sourced. They should give preference to suppliers and sub-contractors that implement eco-friendly practices.

\section{E. Communication}

The research will recommend to event organizers to develop a greening plan which can be used to communicate to the greening team and service providers. They must communicate the greening interventions implemented (e.g.: through materials at the event or through a short presentation at the beginning of the event). Post event, they must compile a report of how the event was greened and lessons learnt.

\section{F. Sustainable Development}

It is in everyone's interest for all businesses, in every industry, to make environmental sustainability a management competency and an aspect of organizational excellence. By taking environmental responsibilities seriously, organizations in the sport event industry are uniquely positioned to communicate the value of environmental sustainability to large numbers of people. Fulfilling environmental responsibilities can help the firm gain a competitive edge and create greater value for its owners.
Event managers need training on sustainability and how it applies to their daily activities. Sustainability is a difficult subject, and training is required to educate event managers on the impacts of their activities and how they can act to improve sustainability through their work. NGOs such as Groundwork and Business in the community can assist with training and provide case studies from businesses who have implemented successful sustainability initiatives. Following up the training with information and notes for attendees to refer back to, is important in ensuring what is learned is followed up by action.

Thus, in many ways the best way forward may be to adopt some broad form of accreditation such as organic or to develop individually branded supply chains that will give an unique selling point for the event. The benefits from having a formalized, well-articulated green strategy are certain to vary by industry and even by individual business, but early adopters can still harness the enormous potential to opportunistically position them with a sustainable green strategic advantage. It is essential to develop techniques in order to make informed decisions, but in a commercial world probably the best approach is to adopt a broad set of criteria that are likely to give environmental benefits both to the business, the consumer and broader society. This may well be difficult, particularly given that many of the benefits of green supply chains, such as decreased pollution, increase water quality or decreased production of green house gasses are not effectively quantified in an economic way in the marketplace.

\section{ACKNOWLEDGMENT}

The authors gratefully acknowledge contribution by the Dean of the Faculty of Business Management, Universiti Teknologi MARA, Malaysia and their colleagues, family and friends for the support and guidance which have significantly contributed to the quality of this study.

\section{REFERENCES}

[1] J. Allen, W. O'Toole, I. McDonnell, and R. Harris, Festival and Special Event Management, 2nd ed. Milton, Queensland: Wiley. 2002.

[2] S. Beer and C. Lemmer, "A critical review of 'green' procurement: Life cycle analysis of food products within the supply chain," Worldwide Hospitality and Tourism Themes, vol. 3, no. 3, pp. 229-244, 2011.

[3] S. Bergin-Seers and J. Mair, "Emerging green tourists in Australia: their behaviours and attitudes," Tourism and Hospitality Research, vol. 9, no. 2, pp. 109-119, 2009.

[4] H. Bergsteiner and G. C. Avery, "A theoretical responsibility and accountability framework for CSR and global responsibility," Journal of Global Responsibility, vol. 1, no. 1, pp. 8-33, 2010.

[5] C. Jones, "Festivals and events in emergent economies: A sea change, and for whom?" International Journal of Event and Festival Management, vol. 3, iss. 1, pp. $9-11,2012$.

[6] J. Carlsen and A. Taylor, "Mega-events and urban renewal: the case of the Manchester 2002 Commonwealth Games," Event Management, vol. 8, no. 1, pp. 15-22. 2003.

[7] D. Chernushenko, "Greening our games: running sports events and facilities that won't cost the earth," Centurion Publishing and Marketing, Ottawa, 1994.

[8] J. Esquer-Peralta, L. Velazquez, and N. Munguia, "Perceptions of core elements for sustainability management systems (SMS)," Management Decision, vol. 46, no. 7, pp. 1027-1038, 2008.

[9] F. Figge, T. Hahn, S. Schaltegger, and M. Wagner, "The Sustainability Balanced Scorecard - linking sustainability management to business strategy," Business Strategy and the Environment, vol. 11, no. 5, pp. 269-284, 2002.

[10] X. Font, "Environmental certification in tourism and hospitality: progress, process and prospects," Tourism Management, vol. 23, no. 3, pp. 197-205, 2002. 
[11] D. Getz, Festivals, Special Events and Tourism, New York: Van Nostrand Reinhold, 1991.

[12] J. Goldblatt, Special Events: Best Practices in Modern Event Management, 2nd ed. New York: Van Nostrand Reinhold, 1997.

[13] A.-M. Hede, "Managing special events in the new era of the triple bottom line," Event Management, vol. 11, no. 1-2, pp. 13-22, 2008.

[14] S. Henderson, "The development of competitive advantage through sustainable event management," Worldwide Hospitality and Tourism Themes, vol. 3, no. 3, pp. 245-257, 2011.

[15] J. Laing and W. Frost, "How green was my festival: Exploring challenges and opportunities associated with staging green events," International Journal of Hospitality Management, vol. 29, pp. 261-267, 2010.

[16] L. Yu, C. L. Wang, and J. Seo, "Mega event and destination brand: 2010 Shanghai Expo," International Journal of Event and Festival Management, vol. 3, iss. 1, pp. 46-65, 2012.

[17] J. Musgrave, "Moving towards responsible events management," Worldwide Hospitality and Tourism Themes, vol. 3, no. 3, $2011 \mathrm{a}$.

[18] J. Musgrave, "Moving towards responsible events management," Worldwide Hospitality and Tourism Themes, vol. 3, no. 3, pp. 258-274, 2011b.

[19] T. Mysen, "Sustainability as corporate mission and strategy," European Business Review, vol. 24, no. 6, pp. 496-509, 2012.

[20] E. G. Olson, "Creating an enterprise-level "green" strategy," Journal of Business Strategy, vol. 29, no. 2, pp. 22-30, 2008.

[21] M. Paterson and S. Ward, "Roundtable discussion: applying sustainability legislation to events," Worldwide Hospitality and Tourism Themes, vol. 3, no. 3, pp. 203-209, 2011.

[22] J. R. B. Ritchie and B. H. Smith, "The impact of a mega-event on host region awareness: a longitudinal study," Journal of Travel Research, vol. 30, no. 3, pp. 3-10, 1991.

[23] J. Swarbrooke, Sustainable Tourism Management, CABI, New York, 1998.

[24] O. Timsheva. (2001). Environmental legacy of the Olympic Games. Report on the International Olympic Academy's Special Sessions and
[Online].

http://www.ioa.org.gr/books/reports/2001/R2001_116.pdf

[25] D. Weaver, Sustainable Tourism: theory and Practice, Butterworth Heinemann, Oxford, 2006.

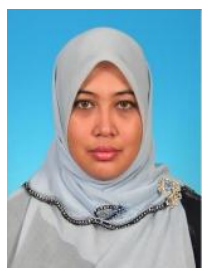

Nor Lela Ahmad is a lecturer teaching at Universiti Teknologi MARA, Puncak Alam, Malaysia. She was born in Perak, raised in Kedah and currently residing in Shah Alam. She holds a master in Business Administration obtained from Universiti Industri Selangor and a bachelor of business administration (Hons.) in Human Resource Management holder from Universiti Teknologi MARA. She has 10 years' experience in the industry prior to joining the education field. Her work experience spans from local to multi-national companies. She began her career in ICI Paints (M) Sdn. Bhd. then moved to Federal Express (M) Sdn. Bhd and Kumpulan Karangkraf Sdn. Bhd. Her last organization was DHL Supply Chain (M) Sdn. Bhd. She joined Universiti Teknologi MARA or UiTM in 2003 teaching students in Bachelor of Event Management (Hons) subjects such as Event Conceptualization and Planning, Budget and Cost Control in Events, Issues in Event Coordination, Legal Issues for Event Professionals and Event Organization. Her teaching portfolio also includes business management subjects such as Introduction to Human Resource Management, Human Resource Utilization, Organizational Behavior, Management of Change and Personality Development. Her areas of expertise are in Human Resource Management, Business Management and Event Management. Her current research activities include studies on Lifelong Learning Event Management Education Model, Green Event Management Model, Strategies to Retain Human Talent through Knowledge Transfer and Determinants of Virtual Team Performance. 